\title{
Study of the Au-Cr bilayer system using x-ray reflectivity, GDOES and ToF-SIMS
}

Philippe Jonnard ${ }^{1}$, Mohammed H. Modi ${ }^{2}$, Karine Le Guen ${ }^{1}$, Nargish Aneshwari ${ }^{2}$, Mangalika

Sinha ${ }^{2}$, Mourad Idir $^{3}$, Patrick Chapon ${ }^{4}$, Anouk Galtayries ${ }^{5}$

${ }^{1}$ Sorbonne Université, Faculté des Sciences et Ingénierie, CNRS UMR 7614, Laboratoire de Chimie Physique - Matière et Rayonnement, 4 place Jussieu, F-75252 Paris cedex 05, France

${ }^{2}$ Soft X-ray Applications Lab, Raja Ramanna Centre for Advanced Technology, Indore 452013, India

${ }^{3}$ Brookhaven National Laboratory - NSLS II, Upton, NY 11973-5000 - USA

${ }^{4}$ HORIBA Scientific, Avenue de la Vauve, Passage Jobin YvonCS 45002, 91120 Palaiseau, France

${ }^{5}$ Chimie ParisTech, PSL Université Paris, CNRS, Institut de Recherche de Chimie Paris (IRCP), 11 rue Pierre et Marie Curie, F-75005 Paris, France

\section{Abstract}

We study a Au $(25 \mathrm{~nm}) / \mathrm{Cr}(10 \mathrm{~nm})$ bilayer system as a model of mirror for the soft x-ray energy range. The $\mathrm{Au}$ and $\mathrm{Cr}$ thin films are a few nanometers thick and are deposited on a float glass substrate. The sample is characterized using three complementary techniques: soft $x$-ray reflectivity (XRR), glow discharge optical emission spectrometry (GDOES) and time of flight secondary ion mass spectroscopy (ToF-SIMS). XRR provides information about the thickness and roughness of the different layers while GDOES is used to obtain the elemental depth profile of the stack and ToF-SIMS to obtain the elemental and chemical depth profile. GDOES and ToF-SIMS have both a nanometer depth resolution. A coherent description of the bilayer stack is obtained through the combination of these techniques. It consists in five layers namely a surface contamination layer, a principal gold layer, a Au-Cr mixed layer, a $\mathrm{Cr}$ layer and another contamination layer at the top of the substrate.

Keywords: x-ray mirror; gold; chromium; x-ray reflectivity; ToF-SIMS; GDOES 


\section{Introduction}

Gold thin films are used in grazing incidence $\mathrm{x}$-ray reflectivity mirrors in the $100-1500 \mathrm{eV}$ soft $\mathrm{x}$ ray region on synchrotron beamlines because of its flat reflectivity performance [1]. In order to provide a good adhesion with silicon or fused silica substrates, a binding layer of chromium is often used. These mirrors should exhibit no interdiffusion in order to get high and stable performances and thus need to be carefully characterized. To this purpose we use a combination of non-destructive techniques: soft x-ray reflectivity (XRR), glow discharge optical emission spectroscopy (GDOES) and time of flight secondary ion mass spectrometry (ToF-SIMS). The main goal is to determine the thickness of the different layers and interlayers and get some knowledge about the interactions between the layers or at the top of the substrate or at the top of the stack. This kind of methodology has been already used successfully for the study of nanometer periodic multilayers designed for x-ray optics, see Refs. [2-6] for example.

\section{Experimental details}

The $\mathrm{Au} / \mathrm{Cr}$ bilayer sample was prepared by electron beam evaporation from high purity $\mathrm{Au}$ and $\mathrm{Cr}$ targets. Its designed structure was : $\mathrm{Au} / \mathrm{Cr} / \mathrm{SiO}_{2}$ substrate. $25 \mathrm{~nm}$ Au and $10 \mathrm{~nm} \mathrm{Cr}$ layer thicknesses were targeted, respectively. The substrate was a float glass. After its preparation the sample was stored in ambient conditions.

XRR measurements [7] were performed at the reflectivity beamline BL3 [8] of Indus-2 synchrotron radiation source. A monochromatic $1500 \mathrm{eV}$ incident photons irradiated the sample and $\theta-$ $2 \theta$ scans were recorded from 0 to $16^{\circ}$. The intensity reflected by the sample, as measured by a silicon photodiode detector (International Radiation Detector Inc.) having a $100 \%$ internal quantum efficiency, was normalized to the one obtained without sample to obtain the reflectance value. A nickel mesh of $90 \%$ transmission was mounted prior to the sample to measure the time variation of the incident photon flux. This enables one to account the effect of photon flux variation due to the fall in electron beam current in the storage ring. The fit of the XRR curve enable getting structural information about the studied stacks: thickness, density and roughness of the various layers.

The GDOES experiment [9] was performed with an apparatus Profiler 2 from Horiba Scientific. A $30 \mathrm{~W}$ pulsed RF power generated a plasma in Ar gas which pressure was $500 \mathrm{~Pa}$. The pulse frequency and duty cycle were $3000 \mathrm{~Hz}$ and 0.25 repsectively. The plasma is used to both sputter the sample and excite the elements, making them emit characteristic lines. The width of the glow discharge spot on the sample was $4 \mathrm{~mm}$. It took less than $2 \mathrm{~s}$ to sputter the whole stack. However, the fast acquisition of the optical signal makes it possible to analyse ultra-thin layers.

For the TOF-SIMS analysis [10], performed with an TOF.SIMS V apparatus from ION-TOF GmbH, a $1 \mathrm{keV}, 50 \mathrm{nA} \mathrm{Cs}{ }^{+}$ion beam was used to sputter a crater which size was $300 \times 300 \mu \mathrm{m}$. The analysis was made on a $100 \times 100 \mu \mathrm{m}$ area at the centre of the crater by using $25 \mathrm{keV}, 1 \mathrm{pA} \mathrm{Bi}^{+}$ions. First, a mass sumspectrum was obtained by looking at the time of arrival of the ion on the detector, in order to get all the relevant ions. Then, the intensity of each selected ion (of a given mass) was followed as a function of the sputtering time. This time scale is not simply correlated to the thickness. Let us also note that the difference between the yields of two elements is not related to the difference of concentrations of these two elements (SIMS is not a quantitative technique, mainly due to the matrix effects). The analysis is made by detecting the following positive ions : $\mathrm{Si}^{+}, \mathrm{CsO}^{+}, \mathrm{CsSiO}^{+}, \mathrm{CsCr}^{+}, \mathrm{CsCrO}^{+}, \mathrm{CsAu}^{+}, \mathrm{CsAuCr}^{+}, \mathrm{Cs}_{2} \mathrm{C}^{+}$, $\mathrm{CsNa}^{+}$and $\mathrm{CsCa}^{+}$. The three first ones are chosen to probe the substrate; $\mathrm{CsCrO}^{+}$can indicate the possible 
formation of a $\mathrm{Cr}$ oxide; $\mathrm{CsAuCr}^{+}$can indicate the possible formation of a $\mathrm{AuCr}$ alloy or solid solution; the three last ones are related to contamination and impurities. Except $\mathrm{Si}$, all ions are the combinations of $\mathrm{Cs}$ with the element of interest. $\mathrm{Cs}_{2} \mathrm{C}^{+}$is chosen instead of $\mathrm{CsC}^{+}$owing to its higher yield.

\section{Results and discussion}

Figure 1 shows the measured and fitted soft x-ray reflectivity curves of the sample together. The best fit reveals that the bilayer is made of: $\mathrm{C}(2.0 \mathrm{~nm}) / \mathrm{Au}(23.8 \mathrm{~nm}) / \mathrm{Cr}(10.2 \mathrm{~nm}) / \mathrm{SiO}_{2}$ substrate. The roughness at the three interfaces, $\mathrm{C}$-on- $\mathrm{Au}, \mathrm{Au}-\mathrm{on}-\mathrm{Cr}$ and $\mathrm{Cr}$-on- $\mathrm{SiO}_{2}$ are respectively 0.6, 0.8 and $0.7 \mathrm{~nm}$. The optical indices of bulk $\mathrm{Cr}$ and $\mathrm{SiO}_{2}$ were used, but for the Au film it was necessary to decrease the refractive index, real and imaginary parts, by $3 \%$ with respect to its bulk value. This suggests that the density of the Au film is slightly lower ( $\approx 4 \%)$ than the bulk value.

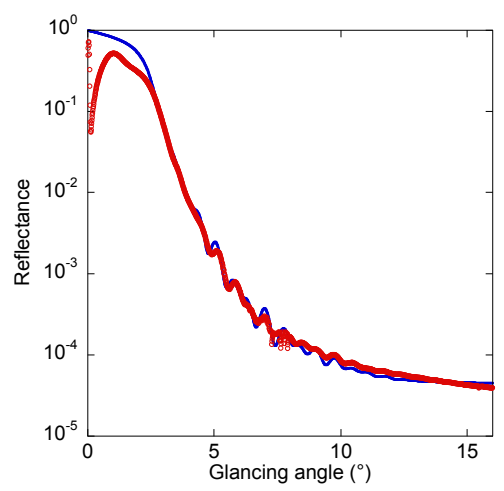

Figure 1: Measured (red dots) and fitted (blue line) soft x-ray reflectivity curves of the $\mathrm{Au} / \mathrm{Cr}$ bilayer sample for $1500 \mathrm{eV}$ incident photon beam.

We show in Figure 2 the GDOES profiles of the $\mathrm{Au}, \mathrm{Cr}$ major elements as well as of $\mathrm{Na}, \mathrm{Ca}, \mathrm{C}, \mathrm{O}$ impurities or contaminants elements. Sodium and calcium are the main impurities of the float glass substrate. Carbon can come from the contamination of the substrate prior the deposition and of the sample after its preparation. Oxygen is present in the glass substrate and in air. Three main zones with two transient zones can be identified:

- $0-0.11 \mathrm{~s}$ : the contaminated surface with the presence of all the studied elements except $\mathrm{Cr}$. While the presence of carbon and oxygen is easily ascribed to the air contamination, this explanation does not hold for sodium and calcium. We suggest these atoms are surfactants and stay above the growing films during the deposition process.

- $0.11-0.53 \mathrm{~s}$ : the Au layer with a rather constant yield, while the yield of the other elements quickly decreases, except the $\mathrm{Cr}$ one increasing quickly at the end of this zone; the $\mathrm{C}$ signal, whose maximum is around $0.08 \mathrm{~s}$, is quickly decreasing in this layer, suggesting no interphase between the contaminated and Au layers.

- $\quad 0.53-0.64 \mathrm{~s}$ : the Au-Cr transient zone marked by an oscillation of the $\mathrm{Cr}$ yield and a $\mathrm{O}$ peak. This could indicate a possible oxidation of the top of the Cr layer; at the end of the zone the decrease of the $\mathrm{Cr}$ yield is in phase with a slight shoulder of the Au yield.

- $\quad 0.64-1.08 \mathrm{~s}$ : the $\mathrm{Cr}$ layer with a yield slightly fluctuating. 
- $1.08-1.22 \mathrm{~s}$ : the $\mathrm{Cr}-\mathrm{SiO}_{2}$ transient zone, where the $\mathrm{Cr}$ signal is decreasing while those of $\mathrm{O}, \mathrm{Na}$ and Ca start to increase. A small peak of the $C$ signal is also observed in this zone. We ascribe it to the superficial contamination of the substrate prior deposition.

- After $1.22 \mathrm{~s}$ : the substrate is reached.

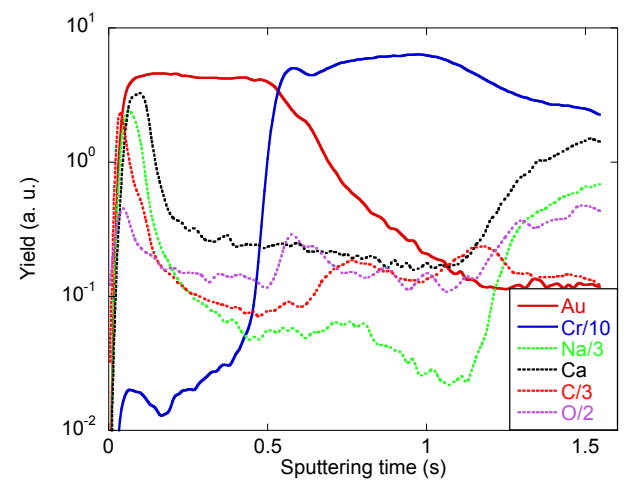

Figure 2: GDOES profiles of the sample. Major elements as well as impurities and contaminants are followed. The signals of $\mathrm{Na}$ and $\mathrm{C}$ are divided by a factor 3, the one of $\mathrm{Cr}$ by 10 and the one of $\mathrm{O}$ by 2 .

We show in Figure 3(a) the $\mathrm{Si}^{+}, \mathrm{CsSiO}^{+}, \mathrm{CsO}^{+}, \mathrm{CsCr}^{+}, \mathrm{CsAu}^{+}, \mathrm{CsAuCr}^{+}, \mathrm{CsNa}^{+}$and $\mathrm{CsCa}^{+} \mathrm{ToF}_{-} \mathrm{SIMS}$ depth profiles and in Figure $3(\mathrm{~b})$ the $\mathrm{Cs}_{2} \mathrm{C}^{+}, \mathrm{CrOCs}^{+}, \mathrm{AuCrCs}^{+}$and $\mathrm{CsCr}^{+}$profiles. As in $\mathrm{GDOES}$, five zones are identified:

- $0-15 \mathrm{~s}$ : contaminated surface; in this zone the sputtering regime is not yet well established; the superficial zone is probed; the profile of the carbon ion is shown after and confirms the existence of the contamination layer determined from the XRR analysis.

- $15-120 \mathrm{~s}$ : Au layer; the $\mathrm{Au}^{+}$yield is constant while those of the other ions are very weak; a low intensity $\mathrm{Cr}$ signal is significantly present as its intensity is higher than that in the silica substrate which can be considered as the background intensity; this SIMS $\mathrm{Cr}$ signal seems related to the low intensity tail of the GDOES Cr signal in the $0.11-0.53$ s range (see Figure 2 ) and thus could show a small diffusion of $\mathrm{Cr}$ atoms toward the Au layer.

- $120-155 \mathrm{~s}$ : Au-Cr transient zone; both signals of $\mathrm{CsAu}^{+}$and $\mathrm{CsCr}^{+}$are present; more interesting the signal of $\mathrm{CsAuCr}^{+}$is present only in this zone; there is also of peak in the $\mathrm{CsO}^{+}$signal as in GDOES and also in the $\mathrm{CsCrO}^{+}$signal.

- $155-210 \mathrm{~s}$ : $\mathrm{Cr}$ layer; the $\mathrm{CsCr}^{+}$yield is more or less constant while those of the other ions are very weak; given the affinity of chromium for oxygen, a superficial oxidation of the $\mathrm{Cr}$ layer can take place owing to the presence of a non-negligible $\mathrm{CsCrO}^{+}$signal, whereas the $\mathrm{CsO}^{+}$signal is minimum.

- $210-270 \mathrm{~s}: \mathrm{Cr}_{-} \mathrm{SiO}_{2}$ transient zone; signals from both the substrate and the $\mathrm{Cr}$ layer are present.

- $270-365 \mathrm{~s}: \mathrm{SiO}_{2}$ substrate; the presence of $\mathrm{Si}^{+}$and $\mathrm{CsO}^{+}$ions is regular; the $\mathrm{CsCr}^{+}$signal drops steeply.

- Charging effect, after $365 \mathrm{~s}$ : after this sputtering time, charging effects coming from the insulating nature of the glass substrate prevent from further analysis under the same conditions. 

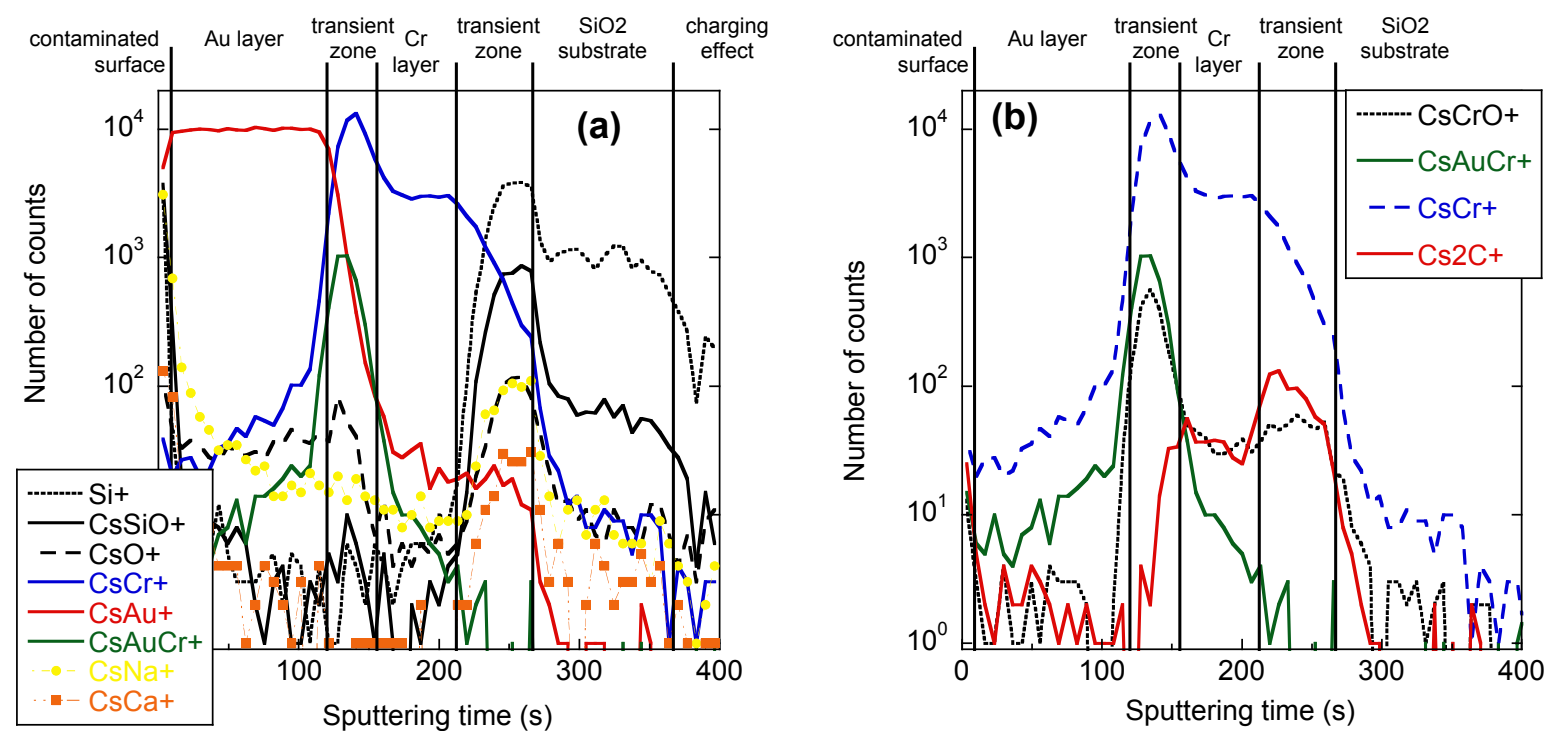

Figure 3: ToF-SIMS profiles of the sample. Major elements as well as impurities are followed.

The $\mathrm{Cs}_{2} \mathrm{C}^{+}$SIMS signal is present in the contaminated layer where it decreases quickly when going deeper. This confirms the carbon presence as due to a surface contamination. The GDOES results confirm the presence of the carbon-contaminated zone. From the $\mathrm{Cs}_{2} \mathrm{C}^{+}$profile it is also clear that some contamination takes place in the $\mathrm{Cr}$ layer and the transient zone between $\mathrm{Cr}$ and the substrate. In the $\mathrm{Au}$ and the mixed Au-Cr layers the intensity of the $\mathrm{Cs}_{2} \mathrm{C}^{+}$signal is negligible. This is also confirmed by GDOES, where the signal of $\mathrm{C}$ is quite intense and shows some amount of carbon in the $\mathrm{Cr}$ layer, not in the mixed $\mathrm{Au}-\mathrm{Cr}$ layer, and in the transient zone with the substrate. The $\mathrm{Na}$ and $\mathrm{Ca}$ impurities are mainly concentrated on top of the glass substrate and on top of the sample. The $\mathrm{CsCrO}^{+}$signal is only related to the $\mathrm{Cr}$ and mainly present at the two interfaces ( $\mathrm{Cr}-\mathrm{Au}$ and $\left.\mathrm{Cr}-\mathrm{SiO}_{2}\right)$.

There is a fair agreement between the structure of the $\mathrm{Au} / \mathrm{Cr} / \mathrm{SiO}_{2}$ sample deduced from XRR, GDOES and ToF-SIMS measurements. The XRR analysis relies on a model of stack to determine the parameters of the different layers. In the fitting process, the roughness between the layers can be due to the geometry (height variation) or the chemistry (interdiffusion) or both of them. So, we ascribe the roughnesses at the $\mathrm{Au}$-on- $\mathrm{Cr}$ and $\mathrm{Cr}$-on-SiO $\mathrm{S}_{2}$ interfaces to the transient zones observed by GDOES and ToF-SIMS. The fitting results are not significantly improved even using a five-layer model, i.e. with Au-on$\mathrm{Cr}$ and $\mathrm{Cr}$-on-SiO $\mathrm{S}_{2}$ interlayers. In fact, the fitting results are rather good with a simple $\mathrm{Au} / \mathrm{Cr}$ two-layer mode with a superficial contamination layer, Fig. 1.

Finally, we compare ToF-SIMS and GDOES profiles in Figure 4(a) for Au and in Figure 4(b) for Cr. To superimpose both curves, the GDOES sputtering time at $0.53 \mathrm{~s}$ is normalized with respect to the one of SIMS at $120 \mathrm{~s}$ and both yields are normalized to unity. The comparison is made on a linear scale. We can see that the SIMS profile presents a better dynamics, a more stable plateau and smaller tail. As expected, given the nano-thicknesses of the deposited layers, ToF-SIMS depth profiling seems better suited for this analysis. The dynamics of the signal is rather the same for GDOES and ToF-SIMS toward the low sputtering times whereas it is better for ToF-SIMS for long sputtering times. We could infer from this, that the ToF-SIMS sputtering process induces less mixing in the sample than the GDOES sputtering process or more probably that it is important to make the analysis without influence of the crater walls. 
Indeed in ToF-SIMS the detected ions come from the centre of the crater (see the experimental details section) while in GDOES the detected signals come from the whole sputtered surface. It is interesting to note that both techniques give a $\mathrm{Cr}$ yield increase at the $\mathrm{Au}$-on- $\mathrm{Cr}$ interface (around $130 \mathrm{~s}$ ), however with much different amplitudes.
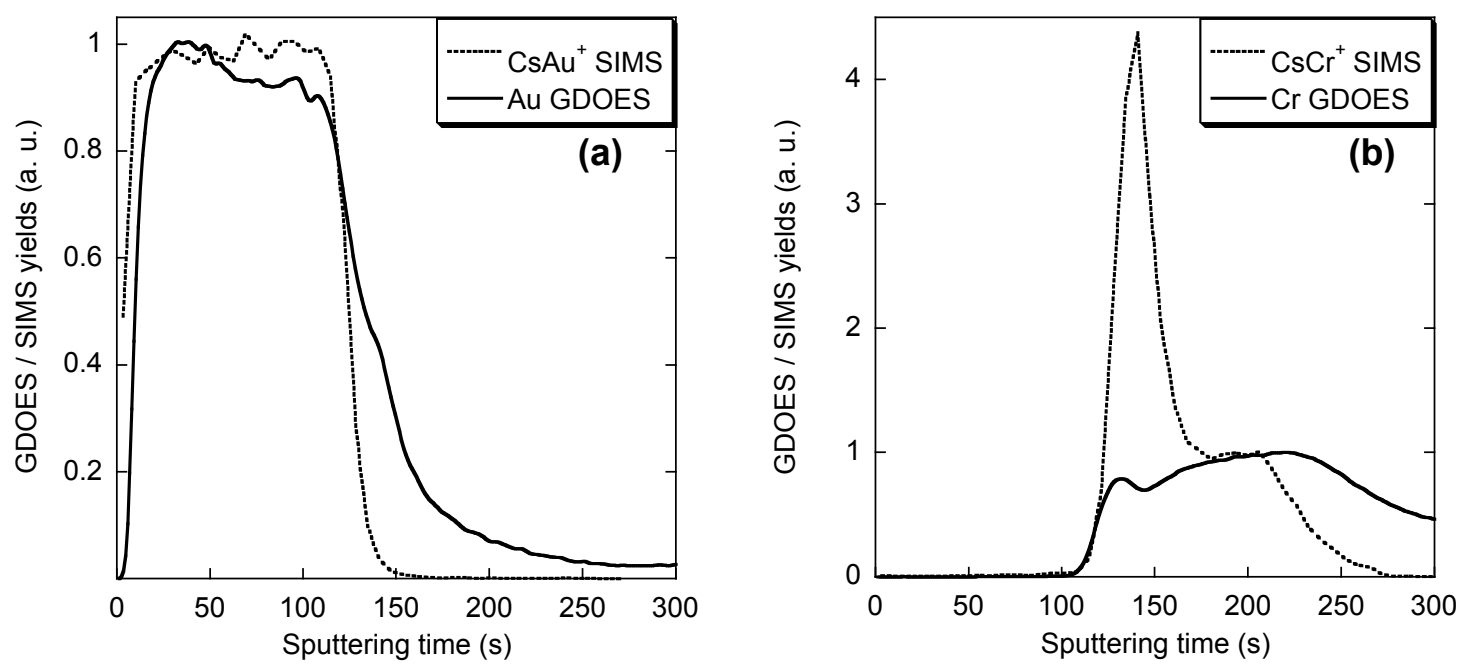

Figure 4: Comparison on a linear scale of the ToF-SIMS (dotted line) and GDOES (solid line) profiles of Au (a) and $\mathrm{Cr}$ (b) elements. The GDOES sputtering time is normalized to the ToF-SIMS one.

\section{Conclusion}

A coherent description of the $\mathrm{Au} / \mathrm{Cr} / \mathrm{SiO}_{2}$ sample has been obtained by combining XRR, GDOES and ToF-SIMS measurements. XRR, which is non-destructive, enables getting the thickness of the different layers and interlayers as well determining that the gold film is slightly less dense than gold bulk. GDOES measurements are fast and enable obtaining elemental depth profiles of the major and minor elements of the sample. ToF-SIMS depth profiles present a larger dynamic range and bring supplementary chemical information in addition to the elemental one, particularly at the interfaces, as the association of an ion with another element can be detected. Finally, the structure of the sample, from the top to the bottom is:

- superficial layer, $2 \mathrm{~nm}$ thick, contaminated with oxygen and carbon; $\mathrm{Na}$ and $\mathrm{Ca}$ atoms are present as impurities coming from the substrate;

- gold layer, $24 \mathrm{~nm}$ thick, having slightly lower density that of bulk gold;

- Au-Cr transient layer, about $0.8 \mathrm{~nm}$ thick, where it is possible to find some $\mathrm{AuCr}$ mixing and oxidation of chromium on one or two layers (most probably $\mathrm{Cr}^{3+}$ );

- chromium layer, $10 \mathrm{~nm}$ thick, contaminated with some carbon;

- $\mathrm{Cr}-\mathrm{SiO}_{2}$ substrate transient layer, about $0.7 \mathrm{~nm}$ thick; $\mathrm{Na}$ and $\mathrm{Ca}$ atoms are present as impurities on top of the substrate which is also contaminated by a small amount of carbon;

- float glass substrate.

Such a study shows the interest of combining complementary techniques in order to determine the in-depth composition of nanometer-thick multilayer stacks. The penetration depth of the radiation in gold being around $10 \mathrm{~nm}$ when used in total reflection mode, i.e. used as an x-ray mirror, our results 
show that the choice of the thickness of the gold layer, $20 \mathrm{~nm}$, was relevant. Indeed the presence of the interdiffusion layer at the Au-on-Cr interface would have deteriorated the optical performance of the stack if the gold layer would have been $10 \mathrm{~nm}$-thick or thinner. This could be also the case if the mirror would be subject to a high thermal load, as it is generally the case for the first mirrors on synchrotron beamlines, which would broaden the interdiffusion zone.

\section{References}

1. Attwood, D. (2000) Soft X-Rays and Extreme Ultraviolet Radiation, Cambridge University Press.

2. Galtayries, A., Hu, M. -H., Le Guen, K., André, J. -M., Jonnard, P., Meltchakov, E., Hecquet, C., and Delmotte, F. (2010) Nanometer-designed Al/SiC periodic multilayers: characterization by a multitechnique approach. Surf. Interface Anal., 42 (6-7), 653-657.

3. Galindo, R.E., Gago, R., Duday, D., and Palacio, C. (2010) Towards nanometric resolution in multilayer depth profiling: a comparative study of RBS, SIMS, XPS and GDOES. Anal. Bioanal. Chem., 396 (8), 2725-2740.

4. Le Guen, K., Hu, M.-H., André, J.-M., Jonnard, P., Wang, Z., Zhu, J., Galtayries, A., Meny, C., Meltchakov, E., Hecquet, C., and Delmotte, F. (2011) Characterization of EUV periodic multilayers. X-Ray Spectrom., 40 (5), 338-342.

5. Ber, B., Bábor, P., Brunkov, P.N., Chapon, P., Drozdov, M.N., Duda, R., Kazantsev, D., Polkovnikov, V.N., Yunin, P., and Tolstogouzov, A. (2013) Sputter depth profiling of Mo/B4C/Si and Mo/Si multilayer nanostructures: A round-robin characterization by different techniques. Thin Solid Films, $\mathbf{5 4 0}$ (Supplement C), 96-105.

6. Yuan, Y., Le Guen, K., André, J.-M., Mény, C., Ulhaq, C., Galtayries, A., Zhu, J., Wang, Z., and Jonnard, P. (2015) Interface observation of heat-treated Co/Mo2C multilayers. Appl. Surf. Sci., 331, 8-16.

7. Daillant, J., and Gibaud, A. (eds.) (2008) X-ray and Neutron Reflectivity: Principles and Applications, Springer.

8. Modi, M.H. (2015) Design, development and commissioning of "Soft X-ray Reflectivity Beamline" at Indus-2. RRCAT Newsl., 28 (2), 3.

9. Nelis, T., and Pallosi, J. (2006) Glow Discharge as a Tool for Surface and Interface Analysis. Appl. Spectrosc. Rev., 41 (3), 227-258.

10. Fearne, S. (2015) An Introduction to Time-of-Flight Secondary lon Mass Spectrometry (ToF-SIMS) and its Application to Materials Science, IOP Publishing. 